Article

\title{
Elevation-Dependent Vegetation Greening of the Yarlung Zangbo River Basin in the Southern Tibetan Plateau, 1999-2013
}

\author{
Haidong $\mathrm{Li}^{1,2}$, Yingkui Li ${ }^{2, *}$, Weishou Shen ${ }^{1}$, Yanan $\mathrm{Li}^{2}$, Jie Lin ${ }^{3}$, Xiaoyu Lu ${ }^{2}$, Xia Xu ${ }^{4,5}$ and \\ Jiang Jiang $3,6, *$
}

Received: 26 October 2015; Accepted: 1 December 2015; Published: 8 December 2015

Academic Editors: Alfredo R. Huete and Prasad S. Thenkabail

1 Nanjing Institute of Environmental Sciences, Ministry of Environmental Protection, Nanjing 210042, China; Lihd2020@163.com (H.L.); Shenweishou@163.com (W.S.)

2 Department of Geography, University of Tennessee, Knoxville, TN 37996, USA; yli49@vols.utk.edu (Y.L.); xlu14@vols.utk.edu (X.L.)

3 Collaborative Innovation Center of Sustainable Forestry in Southern China of Jiangsu Province, Nanjing Forestry University, Nanjing 210037, China; linjiecn@gmail.com

4 Department of Ecology, Evolution and Organismal Biology, Iowa State University, Ames, IA 50011, USA; xuxia.1982@yahoo.com

5 College of Biology and the Environment, Nanjing Forestry University, Nanjing 210037, China

6 Department of Microbiology \& Plant Biology, University of Oklahoma, Norman, OK 73019, USA

* Correspondence: yli32@utk.edu (Y.L.); ecologyjiang@gmail.com (J.J.); Tel.: +1-865-974-0595 (Y.L.); +1-405-325-6519 (J.J.)

\begin{abstract}
The Yarlung Zangbo River basin is an important alley to transport moisture from the Indian Ocean to the inner Tibetan Plateau. With a wide range of elevations from $147 \mathrm{~m}$ to over $7000 \mathrm{~m}$ above sea level (a.s.l.), ecosystems respond differently to climate change at various elevations. However, the pattern of elevation-dependent vegetation change and how it responds to recent warming have been rarely reported. Here, we investigated the pattern of vegetation greening at different elevations in this river basin using SPOT normalized difference vegetation index (NDVI) data during 1999-2013, and examined its relationship with elevation-dependent changes in temperature and precipitation. The annual NDVI has increased by 8.83\% from 1999 to 2013. In particular, the NDVI increased more apparently at lower elevations, but remained relatively stable or even decreased at high elevations. It seems that rising temperature has driven the basin-wide vegetation greening, but the greening rate is in contrast to the pattern of elevation-dependent warming (EDW) with more significant temperature increase at higher elevations. It appears that decreasing precipitation does not reverse the overall increasing trend in NDVI, but relatively limited precipitation $(<500 \mathrm{~mm})$ may constrain the NDVI increases, causing apparently stable or even decreased NDVI at higher elevations $(>4000 \mathrm{~m})$.
\end{abstract}

Keywords: vegetation greening; elevation gradient; Tibetan Plateau; climate change; precipitation decrease; normalized difference vegetation index (NDVI); Tropical Rainfall Measuring Mission (TRMM) derived precipitation

\section{Introduction}

Climate change is one of the main, but uncertain, factors that have significant impact on terrestrial ecosystems, inducing vegetation and biodiversity changes, especially in fragile environments [1-5]. Since 1901, global mean surface temperature has increased by $0.89^{\circ} \mathrm{C}$ according to the Fifth Assessment Report of the Intergovernmental Panel on Climate Change (IPCC) [6]. 
This warming trend is complex with large spatial heterogeneity, varying from significant temperature increase at some regions to no change or even cooling at certain regions [7-9]. Evidence also suggests that high-mountain environments are experiencing more rapid warming than lowlands, and this phenomenon is usually referred to as elevation-dependent warming (EDW) $[10,11]$. EDW can accelerate the rate of changes in mountain ecosystems, cryospheric systems, hydrological regimes, and biodiversity $[12,13]$.

Vegetation plays an important role in regulating terrestrial ecosystem [14], and vegetation greenness is commonly used to assess the productivity of natural or agricultural lands [15]. Studies have attributed rising temperature to increasing vegetation productivity over the past decades, especially for ecosystems at mid-, high latitudes, and high altitudes where temperature is the major limiting factor [16-20]. If rising temperature acts as a major driver of vegetation greening in a mountainous environment, a pattern of elevation-dependent vegetation greening (EDVG) would also be expected in response to the EDW. However, climate change in different elevations is not only characterized as rising temperature, but also associated with shifting precipitation regimes [21,22]. For example, some studies have indicated that, compared to temperature, precipitation is more critical for the vegetation growth in arid/semiarid areas $[23,24]$. Due to the variability of temperature, precipitation, and other potential factors, such as permafrost and snow cover, the mechanism is still elusive on how the pattern of EDVG is associated with changes in climatic factors at various elevations [11,22].

The Tibetan (Qinghai-Xizang) Plateau, known as the "Third Pole" of the Earth and the "Water Tower of Asia", is the highest plateau in the world and has been regarded as one of the ideal regions to study climate change $[9,25,26]$. Studies have suggested that the warming rate rise as elevation increases [10], causing higher climate sensitivity and phenological changes in higher elevations, but dominant climatic factors differ considerably across the Tibetan Plateau [2,11,27]. For example, rising temperature is the main factor causing grassland greening on the northern plateau, while wetting is the main factor on the southern regions [28]. Other reports show that the high elevations are getting less snow and rainfall [29], and droughts have threatened the vegetation growth on the southern plateau [30]. For example, the migration of tree line in the Himalayas of the Southern Tibetan Plateau is largely controlled by precipitation, rather than temperature as found in the Alps [31]. Thus, it is of critical importance to understand the pattern of vegetation greening in different regions and elevations of the Tibetan Plateau, and its mechanism in response to the EDW and precipitation.

In this paper, we investigate the pattern of EDVG in the Yarlung Zangbo River (YZR) basin, an important alley to transport moisture from the Indian Ocean to the inner Tibetan Plateau [32], during the past 15 years (1999-2013) and examine how EDW and precipitation affect this pattern. Using NDVI (normalized difference vegetation index) as an indicator of vegetation greenness [33-35], we aim to address three research questions: (1) does NDVI's temporal increasing/decreasing trend depend on elevation? (2) do elevation-dependent temperature and precipitation changes exist in the YZR basin? and (3) would EDVG be explained by EDW effectively? If not, what are the roles of precipitation or other factors on vegetation greening? This study provides useful information to assess the impact of climate change on high elevations and promote a better understanding of ecological protection and restoration on the Tibetan Plateau.

\section{Materials and Methods}

\subsection{Study Area}

The YZR, stretching across the southern edge of the Tibetan Plateau from west to east, China, is about $2057 \mathrm{~km}$ long with a drainage area of $2.4 \times 10^{5} \mathrm{~km}^{2}$. It originates from the Chemayungdung Glacier in the Southcentral Tibet, and is one of the highest rivers in the world with a long narrow west-east drainage basin confined by the Himalayas, Gangdise Shan, Nyainqentanglha Shan, and Tanggula Shan (Figure 1a,b). The YZR flows through the dry and flat region before cutting through 
the Himalayas near Mt. Namcha Barwa (about 7755 m) in the southeast Tibetan Plateau. Then, it turns to the south and passes through the Great Canyon of the Yarlung Zangbo (the deepest valley in the world) [36]. The YZR is called Brahmaputra River after flowing into India. The YZR within the Tibetan Plateau has five tributaries: Dogxung Zangbo River, Nyang Qu River, Lhasa River and Nyang River in the midstream, and Parlung Tsangpo River in the downstream. The Lhasa River basin, which provides major water supplies to the YZR, is the largest sub-basin in the YZR basin (Figure 1c).
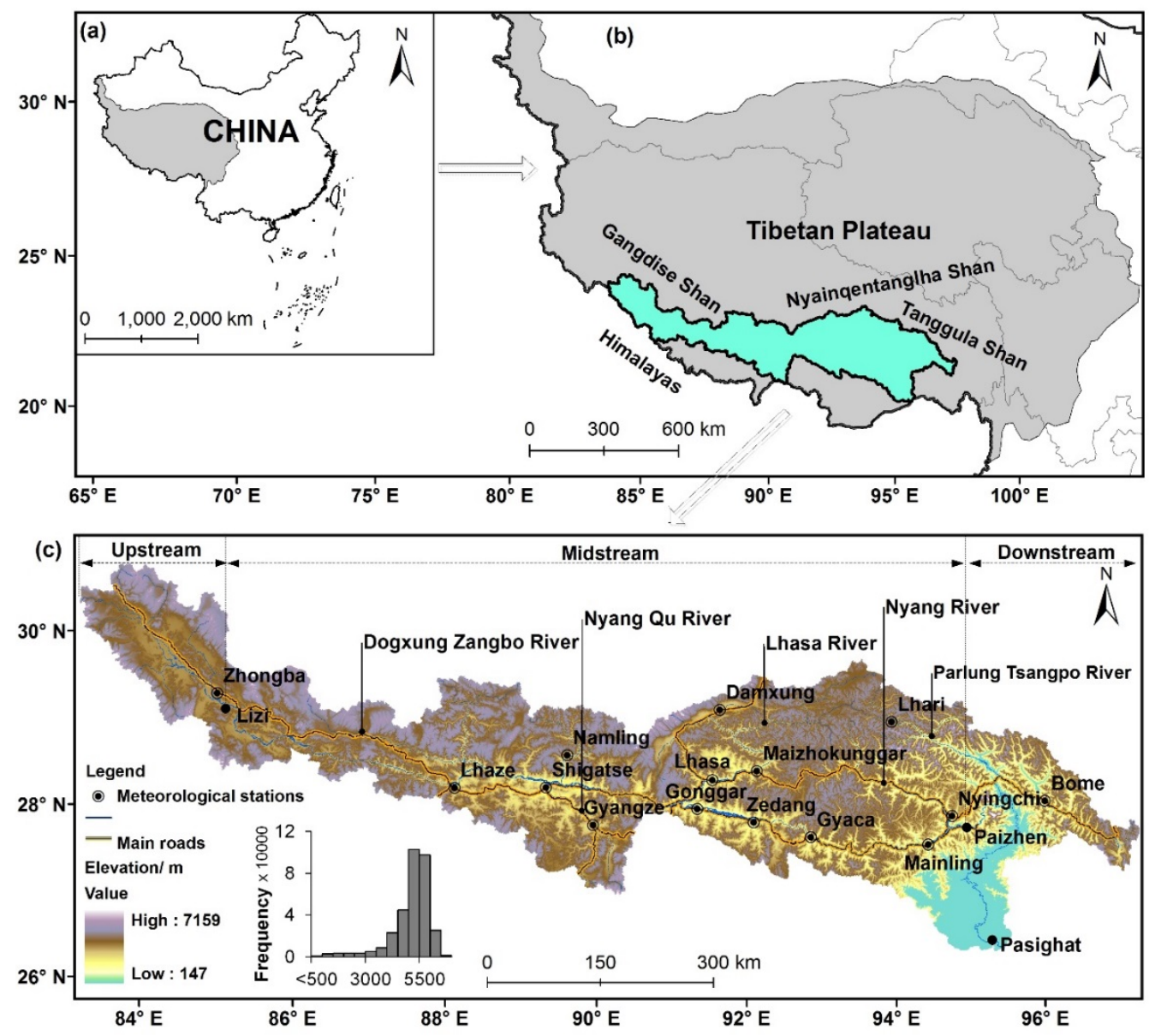

Figure 1. The geographical location of the Yarlung Zangbo River basin in the Tibetan Plateau, China (a,b); and its topographic characteristics represented using the $1 \mathrm{~km}$ resolution SRTM DEM (c). As no meteorological station exists in the upstream of the YZR basin, we use the nearest Gêrzê station to represent the meteorological conditions of Zhongba County.

The YZR basin has a wide range of elevations from $147 \mathrm{~m}$ to over $7000 \mathrm{~m}$ above sea level (a.s.1.), and the average elevation is $4600 \mathrm{~m}$. The YZR basin can be divided into three sub-areas (upstream, midstream, and downstream) and the climatic conditions differ greatly in different sub-areas [37]. The upstream region is defined as the area between Chemayungdung Glacier and Lizi, and is located within a cold and dry temperate steppe climate zone with a multi-year average precipitation of $<300 \mathrm{~mm}$. The midstream region is defined as the area between Lizi and Paizhen, and has a temperate forest-grassland climate with a multi-year average precipitation of 300-600 mm, while the downstream region is defined as the area between Paizhen and Pasighat, and belongs to a warm and humid subtropical climate zone with a multi-year average precipitation reaching $4000 \mathrm{~mm}$ [32]. Both temperature and precipitation exhibited an increasing trend from the headwater region downstream to the low reaches of the basin. The vegetation types present an obvious vertical zoning across the YZR basin [38]. In the upstream regions, the dominant vegetation types are alpine steppe, 
alpine meadow, alpine shrub, and alpine swamp meadow. Similar vegetation types of mountain shrubby-grassland and alpine forests (primary and plantation) occur in the midstream regions [39]. The dominant vegetation types are coniferous forest and broadleaf forest in downstream regions.

The YZR basin contains abundant vegetation patterns and complex climatic conditions at various elevations, and has become a hotspot for studying eco-environment change and vulnerability in response to climate change $[39,40]$.

\subsection{Data Sources}

We used the NDVI dataset derived from the vegetation instrument of the Système Pour l'Observation de la Terre (SPOT-VGT) 4 and 5 satellites (http://www.vgt.vito.be/) to explore inter-annual changes and spatial patterns of vegetation greening during 1999-2013. The spatial resolution of the SPOT NDVI raster is $1 \mathrm{~km}$, and the temporal resolution is about 10 days, which results in 36 NDVI series in a one-year period [41]. The rasters had been pre-processed by the Flemish Institute for Technological Research (VITO) using a consistent processing algorithm including geometric, radiometric, and atmospheric corrections [42]. The maximum value composite (MVC) for each 10-day interval was derived to minimize the non-vegetation effects on SPOT satellite images [43].

The Shuttle Radar Topography Mission (SRTM) digital elevation model (DEM) (http://srtm.csi.cgiar.org/) was used to analyze the topographic characteristics of the YZR basin. The SRTM DEM provides a $90 \mathrm{~m}$ resolution for the world and a $30 \mathrm{~m}$ resolution for the US. The re-sampled SRTM DEMs with resolutions of $250 \mathrm{~m}, 500 \mathrm{~m}$, and $1 \mathrm{~km}$ are also available. To be consistent with the spatial resolution of the SPOT NDVI data, we downloaded the $1 \mathrm{~km}$ resolution SRTM DEM to investigate the relationship between NDVI and elevation gradient.

We collected observed meteorological data (including monthly mean temperature, monthly precipitation) for 1999-2013 from 15 meteorological stations (Figure 1c) across the YZR basin in the China Meteorological Data Sharing Service Network (http://data.cma.gov.cn/). All the meteorological data have been preprocessed based on the hourly observed data, and have a quality control with the accuracy reaching $99.9 \%$.

The meteorological stations were limited in our study area. We actually used all 14 meteorological stations within the YZR basin and included one nearest station outside the upstream of the YZR basin for the analysis. These stations were sparsely distributed and mainly located in the mid- and lower streams. To address the concern that these data may be not sufficient to represent the climatic conditions of the whole basin, we examined the Tropical Rainfall Measuring Mission (TRMM) Multi-satellite Precipitation Analysis 3B43 (monthly $0.25 \times 0.25$ degree merged TRMM precipitation data during 1999-2013) [44], which downloaded from Goddard Earth Sciences Data and Information Services Center (http:/ / mirador.gsfc.nasa.gov /), to analyze the spatiotemporal pattern of precipitation. We also cited publications associated with the pattern of EDW in the YZR, such as Liu et al. (2009) [45] and Qin et al. (2009) [10].

Glacier data were collected from the recent released Second Glacier Inventory of China [46]. Major lake data was obtained from Li et al. (2014) [26].

\subsection{Data Preparation}

To ensure SPOT-VGT NDVI data quality, we excluded the areas of glaciers and major lakes to reduce the noise in NDVI caused by the water bodies. The annual NDVI raster was derived by averaging the 36 NDVI series of each year, and the NDVI data within the YZR basin was extracted from 1999 to 2013. We also calculated the multi-year average NDVI raster through averaging the fifteen annual NDVI rasters during 1999-2013. Based on the NDVI value of each cell in the YZR basin, a spatially averaged value of annual NDVI [19] for each year was derived to analyze the inter-annual change in NDVI. 
The annual mean temperature for each year was calculated through averaging 12 monthly temperatures at each meteorological station, and the annual precipitation for each year was calculated through summing 12 monthly precipitations. We calculated multi-year average temperature and multi-year average precipitation at each meteorological station, respectively, by averaging the fifteen annual mean temperatures or annual precipitations during 1999-2013.

Since the TRMM 3B43 precipitation product is an hourly average precipitation data ( $\mathrm{mm} /$ hour), we first calculated the monthly precipitation ( $\mathrm{mm} / \mathrm{month}$ ) of each pixel through multiplying the hourly precipitation with the total hours in one month, and then summed the 12 monthly precipitation values for each pixel into an annual precipitation (mm/year) for each year. TRMM-derived and station-observed annual precipitation on the Tibetan Plateau are highly correlated $\left(R^{2}=0.79\right)$ [26]. We extracted $225(15 \times 15)$ pixel values of TRMM-derived annual precipitation at all 15 meteorological stations during the past 15 years, and built a regression model between these two datasets. Then, we used this regression model to calibrate the TRMM-derived annual precipitation to obtain a more realistic precipitation pattern.

The areas occupied by glacier and lake were removed to refine the derived NDVI for vegetation greening analysis.

\subsection{Trend Analysis}

We applied a linear regression to detecting the greening rate (changing rate in annual NDVI), the warming rate (changing rate of annual mean temperature), and changing rate of annual precipitation in the YZR basin during 1999-2013. The regression model is as follows:

$$
y=\mathrm{a} t+\mathrm{b}
$$

where $y$ is the annual NDVI, temperature, or precipitation, respectively; $t$ is the year (from 1999 to 2013); $a$ is the slope, indicating the greening rate, the warming rate, or the changing rate of precipitation, respectively; $b$ is the intercept of the regression.

We also evaluated the significance of the trends using the non-parametric Mann-Kendall test (M-K test) [47]. We first defined M-K test statistic $S$ as follows:

$$
S=\sum_{i=1}^{n-1} \sum_{j=x+1}^{n} \operatorname{sign}\left(X_{i}-X_{j}\right)
$$

where, sign() is the sign function; $X_{i}$ and $X_{j}$ are the annual values in year $i$ and $j(i>j)$, respectively, from 1999 to 2013; $n$ equals to 15 , the total number of years. When $X_{i}-X_{j}$ is less than, equal to, or greater than zero, sign $\left(X_{i}-X_{j}\right)$ will be $-1,0$, or 1 correspondingly. A Z-value is calculated using the following equations:

$$
\begin{cases}Z=(S-1) / \sqrt{n(n-1)(2 n+5) / 18} & S>0 \\ Z=0 & S=0 \\ Z=(S+1) / \sqrt{n(n-1)(2 n+5) / 18} & S<0\end{cases}
$$

$Z$-value $>0$ indicates an increasing trend, whereas $Z$-value $<0$ indicates a decreasing trend. The absolute $Z$-value of $\geqslant 1.28, \geqslant 1.64$ or $\geqslant 2.32$ represents the statistical significance at the confidence level of $90 \%, 95 \%$, or $99 \%$, respectively.

\subsection{Exploring NDVI and Climatic Variables}

We plotted the value of multi-year average NDVI, greening rate, TRMM-derived precipitation and precipitation trend against elevation bins, respectively. One elevation bin is defined as an elevation range from $250 \mathrm{~m}$ below to $250 \mathrm{~m}$ above the bin elevation; for example, elevation bin of $500 \mathrm{~m}$ is for an elevation range from $250 \mathrm{~m}$ to $750 \mathrm{~m}$. We also plotted the greening rate against multi-year average NDVI bins. One multi-year average NDVI bin is defined as a multi-year average 
NDVI range from 0.05 below to 0.05 above the bin multi-year average NDVI. These box-and-whisker plots help to examine the patterns among NDVI, elevation, and different climatic factors.

\section{Results}

\subsection{Pattern of NDVI Change in the YZR Basin}

For the whole YZR basin, the annual NDVI shows a fluctuating but significantly increasing trend with a greening rate of $0.0018 \mathrm{y}^{-1}$ at the $99 \%$ confidence level $(Z=3.37)$ (Figure 2). The annual NDVI has increased by $8.83 \%$ from 1999 to 2013 . The highest annual NDVI value is 0.201 in 2013, which is 0.015 higher than the multi-year average NDVI (0.186) in 1999-2013, followed by those in 2011 and 2009 (0.199 and 0.197, respectively). The lowest annual NDVI is 0.170 in 2000 (0.031 lower than the multi-year average in 1999-2013), followed by that in 2002 (0.172).

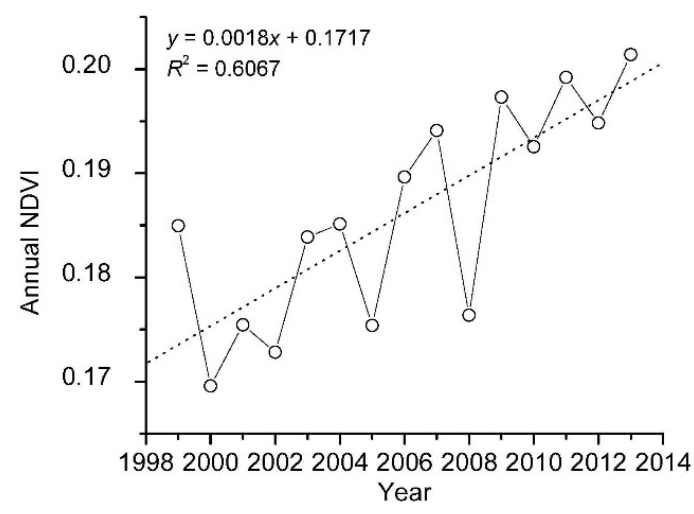

Figure 2. Changes of annual NDVI in the YZR basin from 1999 to 2013.

As shown in Figure 3a, multi-year average NDVI values gradually increase from the upstream region where alpine grassland is sparse and patchy, to the midstream region where shrub-grassland and alpine forest are widely distributed, and to the downstream region where coniferous forest and broadleaf forest are the dominant vegetation types. Multi-year average NDVI values of $>0.4$ account for $8.6 \%$ of the YZR basin, and most of them appear in the downstream. The spatial pattern of greening rates across the YZR basin (Figure $3 b$ ) is similar to that of the multi-year average NDVI as shown in Figure 3a. From 1999 to 2013, the greening rate exhibits an increasing trend in $94.1 \%$ of the YZR basin, of which $51.8 \%$ passed the $95 \%$ confidence level ( $Z>1.64$ ) (Figure 3c). The most pronounced increase exceeding $0.007 \mathrm{y}^{-1}$ appears as narrow belts along wide valleys in the midstream, where large areas of artificial forests were planted in the past 20 years, or as large patches in the lower reaches. In contrast, decreasing NDVI only occurs in $<6.0 \%$ of the basin and appears as small and fragment patches, primarily located in the upstream region, some locations close to Damxung in the upper reaches of the Lhasa River, regions along main roads or around big cities in the midstream, and some low-reach locations with higher elevations (Figure 3b,c).

We examined multi-year average NDVI values in different elevation bins and found that the NDVI values decreases as elevation increase, with the highest value in the elevation bin of $500 \mathrm{~m}$ (Figure 4a). The greening rates slightly increase from elevation bins of $500 \mathrm{~m}$ to $2000 \mathrm{~m}$, then start to decrease from $2000 \mathrm{~m}$ to $4000 \mathrm{~m}$ elevation bins. Above $4000 \mathrm{~m}$ elevation bin, NDVI was relative stable during 1999-2013 (Figure 4b). We also observed that the greening rates are greater when the multi-year average NDVI values are higher (Figure 4c). In particular, in regions where the multi-year average NDVI values are $>0.4$, the greening rates increase significantly; in contrast, the greening rates are relatively constant where the multi-year average NDVI values are $<0.4$. The multi-year average NDVI value of 0.4 roughly corresponds to the elevation bin of $3000 \mathrm{~m}$ (Figure 4a), indicating that the vegetation greening is more apparent in elevation bins of $<3000 \mathrm{~m}$. 

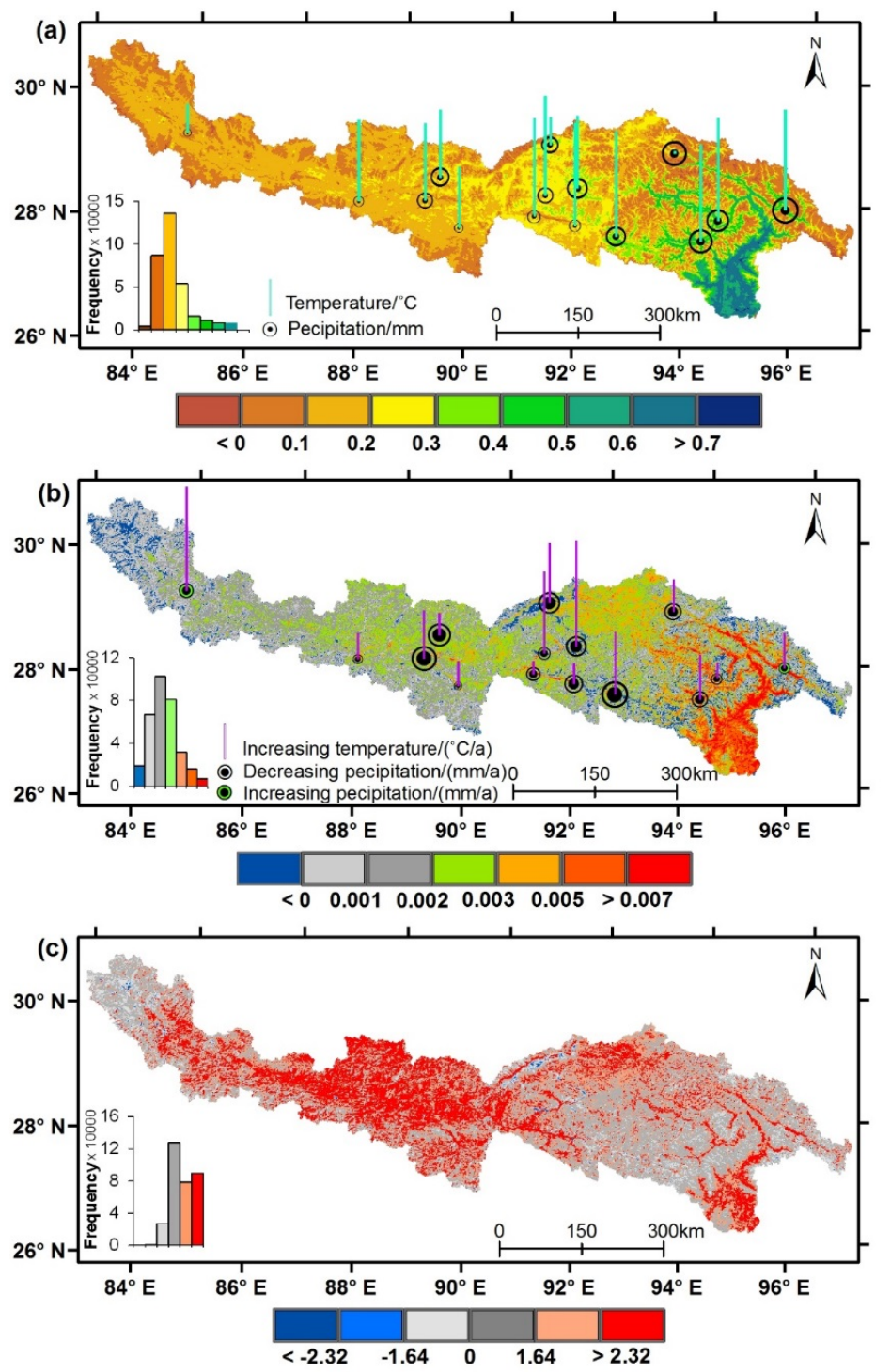

Figure 3. Spatial patterns of multi-year average NDVI (a); greening rate (b); and Z-value (c) in the YZR basin during 1999-2013. (a) The range of annual mean temperatures is from $0.22{ }^{\circ} \mathrm{C}$ to $9.78{ }^{\circ} \mathrm{C}$, and annual precipitation ranges from $200 \mathrm{~mm}$ to $841 \mathrm{~mm}$; and (b) the range of warming rate is $0.011{ }^{\circ} \mathrm{C} \cdot \mathrm{y}^{-1}$ to $0.09{ }^{\circ} \mathrm{C} \cdot \mathrm{y}^{-1}$, and precipitation changing rate ranges from $-17.42 \mathrm{~mm} \cdot \mathrm{y}^{-1}$ to $1.97 \mathrm{~mm} \cdot \mathrm{y}^{-1}$; (c) Z-value was calculated using the $\mathrm{M}-\mathrm{K}$ test, and the absolute $Z$ values of $\geqslant 1.64$ and $\geqslant 2.32$ indicate the confidence level $95 \%$ and $99 \%$, respectively.

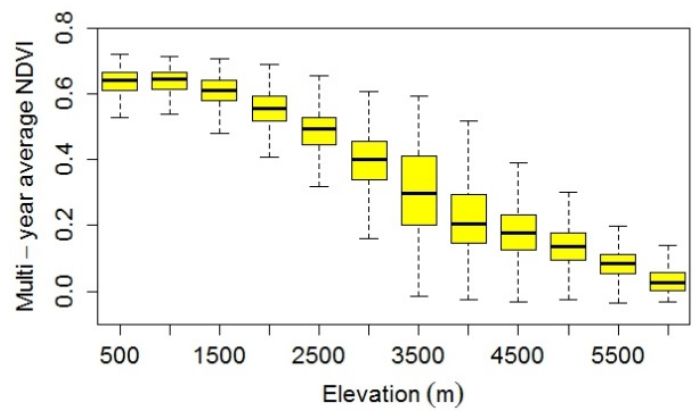

(a)

Figure 4. Cont. 


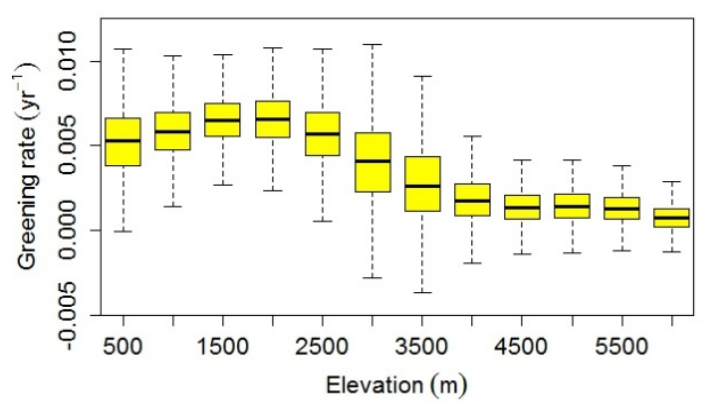

(b)

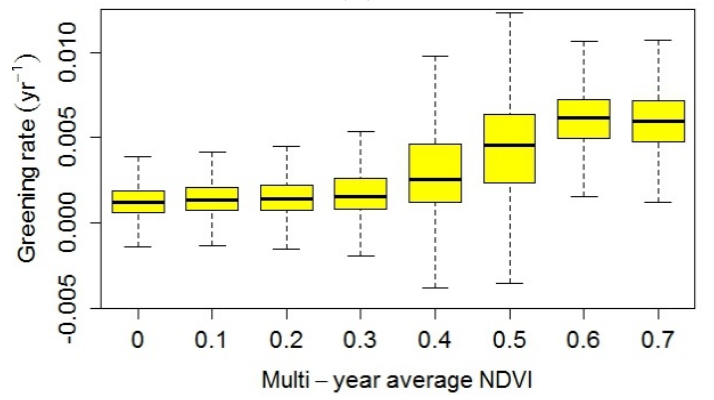

(c)

Figure 4. Elevation-dependent pattern of multi-year average NDVI (a) and greening rate (b); and the relationship between greening rate and multiyear average NDVI (c) in the YZR basin during 1999-2013. The box-and-whisker plot is produced from the 25th to 75th percentiles at the ends of the box, the median is indicated with a horizontal line in the interior of the box, and the maximum and minimum are at the ends of the whiskers.

\subsection{Elevation-Dependent Pattern of Temperature and Precipitation Changes}

The multi-year average temperature ranges from $0.22{ }^{\circ} \mathrm{C}$ to $9.78{ }^{\circ} \mathrm{C}$ in the $\mathrm{YZR}$ basin during 1999-2013 based on the observational data from the 15 meteorological stations (Figures 3a and 5a). For the whole YZR basin, the annual mean temperature exhibits an overall increasing trend $(Z=1.48$, reaching the confidence level of 90\%) during 1999-2013, with the highest value of $7.66{ }^{\circ} \mathrm{C}$ in 2009 and a warming rate of $0.039^{\circ} \mathrm{C} \cdot \mathrm{y}^{-1}$ (Figure 6a). The annual mean temperature exhibits similar increasing trend during 1999-2013 in all 15 meteorological stations (Figure 3b), and decreases significantly as elevation increases from $2500 \mathrm{~m}$ to $4500 \mathrm{~m}$, with a trend reaching the $99 \%$ confidence level $(Z=-3.76)$ (Figure 5a). The warming rate varies from $0.011{ }^{\circ} \mathrm{C} \cdot \mathrm{y}^{-1}$ to $0.09{ }^{\circ} \mathrm{C} \cdot \mathrm{y}^{-1}$, with a slightly (but not statistically significant) increasing trend from low to high elevations (Figure $5 b$ ).

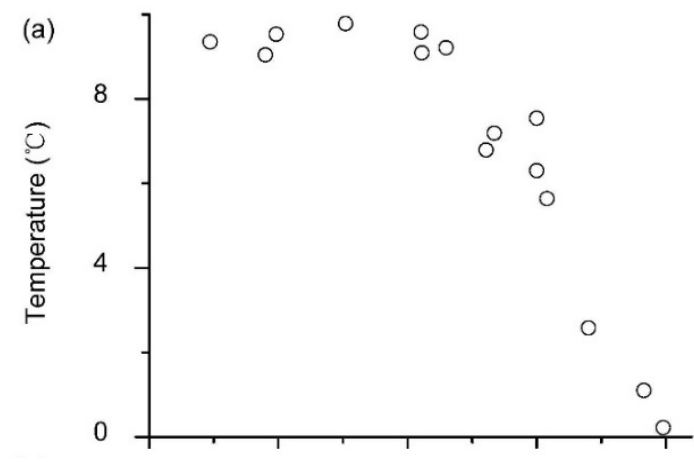

Figure 5. Cont. 

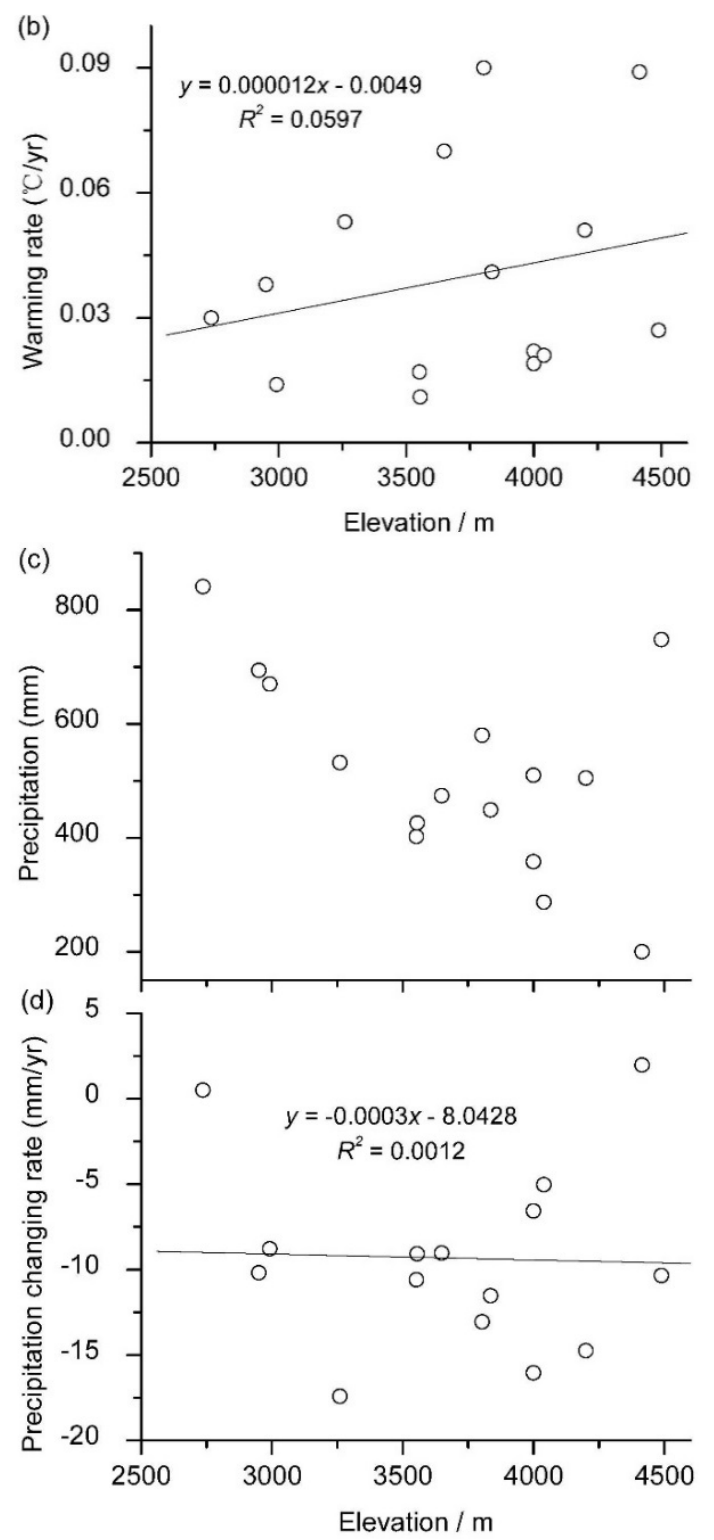

Figure 5. Variations of annual mean temperature (a); warming rate (b); annual precipitation (c); and precipitation changing rate (d) against elevation from $2500 \mathrm{~m}$ to $4500 \mathrm{~m}$, respectively, during 1999-2013. Each circle represents one value from each meteorological station in the YZR basin.

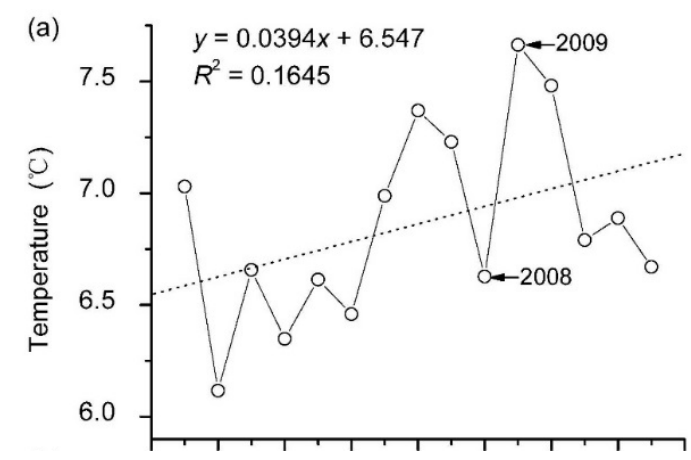

Figure 6. Cont. 


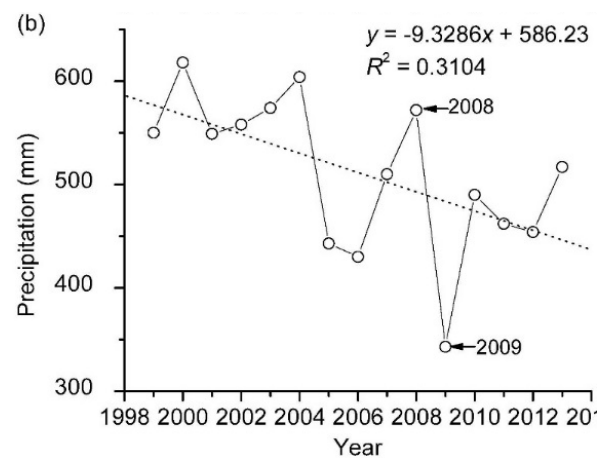

Figure 6. Changes in annual mean temperature (a) and annual precipitation (b) within the YZR basin from 1999 to 2013.

From 1999 to 2013, the multi-year average precipitation observed from the 15 meteorological stations ranges from $200 \mathrm{~mm}$ to $841 \mathrm{~mm}$ (Figures 3a and 5c). For the whole YZR basin, the annual precipitation decreases significantly at the $95 \%$ confidence level $(Z=-1.78)$, with the smallest value of $343 \mathrm{~mm}$ occurred in 2009 and a changing rate of $-9.33 \mathrm{~mm} \cdot \mathrm{y}^{-1}$ (Figure 6b). Specifically, 13 out of 15 meteorological stations have the similar decreasing trends (Figure $3 \mathrm{~b}$ ). The annual precipitation of each station decreases significantly as elevation increases from $2500 \mathrm{~m}$ to $4500 \mathrm{~m}$, reaching the $95 \%$ confidence level $(Z=-1.88)$ (Figure $5 \mathrm{c}$ ). The rate of precipitation change varies from $-17.42 \mathrm{~mm} \cdot \mathrm{y}^{-1}$ to $1.97 \mathrm{~mm} \cdot \mathrm{y}^{-1}$, with a slightly decreasing trend from low to high elevations (Figure $5 \mathrm{~d}$ ).

TRMM-derived precipitation and station-observed precipitation are highly correlated $\left(R^{2}=0.7796\right.$, Figure 7$)$, indicating that TRMM-derived precipitation can be used to interpret spatial and temporal trends in precipitation. It appears that TRMM-derived precipitation is higher than station-observed precipitation in this basin. We used the regression model to calibrate the TRMM precipitation. The calibrated TRMM precipitation increases gradually from the upstream to the downstream, ranging from $230 \mathrm{~mm}$ to the maximum of $2297 \mathrm{~mm}$ (Figure 8a). Only 28.3\% of calibrated TRMM precipitation exhibits a similar trend with the greening rate of the YZR basin during 1999-2013, and 71.7\% shows an opposite trend (Figures 3b and 8b), of which mainly occurs in the regions with TRMM precipitation from $400 \mathrm{~mm}$ to $700 \mathrm{~mm}$ (Figure 8a).

Regions with precipitation $<500 \mathrm{~mm}$ approximately account for $54.5 \%$ of the river basin, while with precipitation $>800 \mathrm{~mm}$ only take up to $13.4 \%$, mainly occurring in the downstream where elevation bins are $<3500 \mathrm{~m}$ (Figure 8c). Similar to the trend observed from stations, calibrated TRMM precipitations also decrease significantly as elevation increases from $500 \mathrm{~m}$ to $6000 \mathrm{~m}(p<0.05)$. The changing rates of calibrated TRMM precipitation range from $-10 \mathrm{~mm} \cdot \mathrm{y}^{-1}$ to $0 \mathrm{~mm} \cdot \mathrm{y}^{-1}$ (median value), without a clear dependence with elevation (Figure 8d).

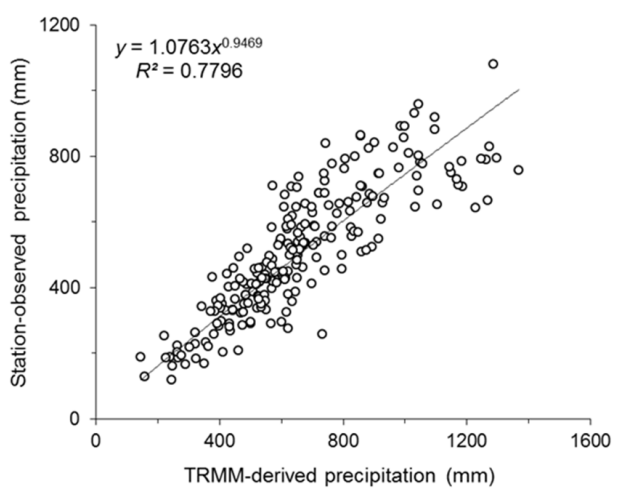

Figure 7. Relationship between TRMM-derived precipitation and observed precipitation from metrological stations in the YZR basin during 1999-2013. 

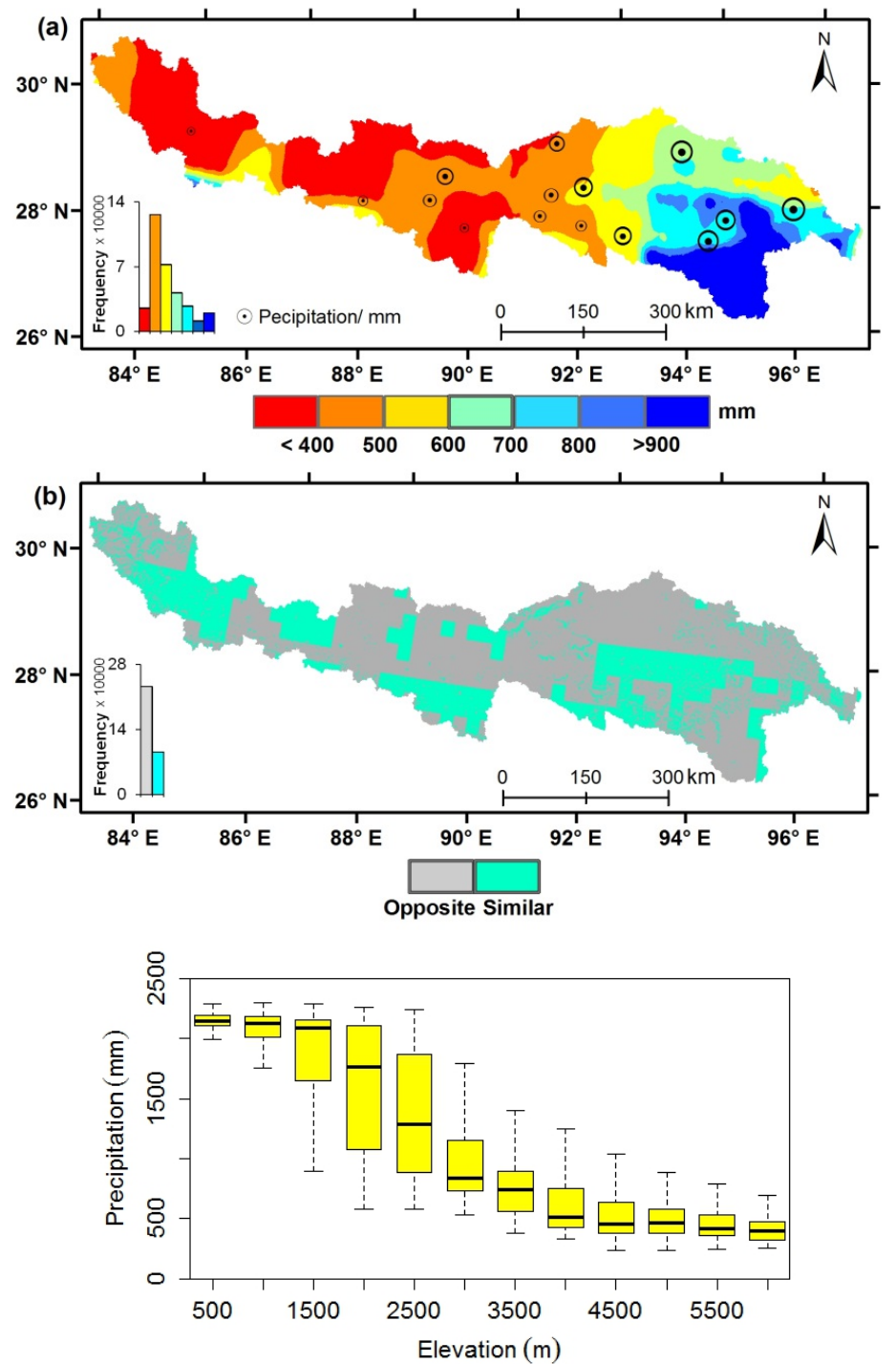

(c)

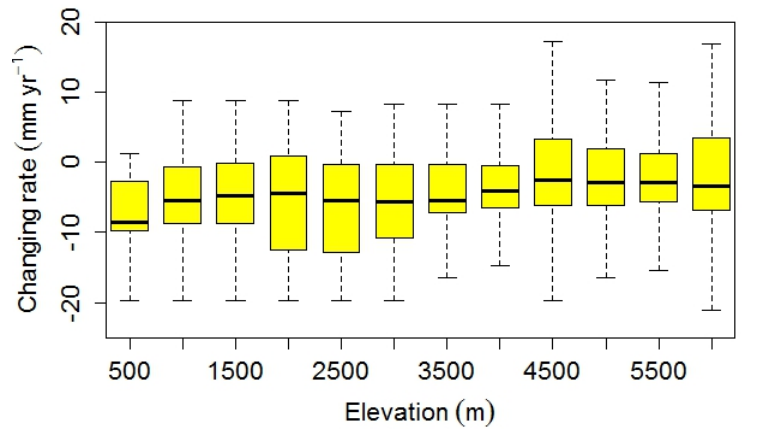

(d)

Figure 8. Spatial distribution of TRMM-derived precipitation (a); trend analysis between TRMM-derived precipitation changing rate and greening rate (b); vertical pattern of TRMM-derived precipitation (c); and TRMM-derived precipitation changing rate (d) against elevation from $500 \mathrm{~m}$ to $6000 \mathrm{~m}$ in the YZR basin during 1999-2013. (a) The range of station-observed precipitation is from $200 \mathrm{~mm}$ to $841 \mathrm{~mm}$; (b) the grey means an opposite trend, the cyan indicates a similar trend; (c,d) the box-and-whisker plot is produced from the 25th to 75th percentiles at the ends of the box, the median is indicated with a horizontal line in the interior of the box, and the maximum and minimum are at the ends of the whiskers. 


\section{Discussion}

Climate change is one of the main drivers of the changes in vegetation productivity in many regions around the world [48-50]. In the YZR basin, vegetation greening shows an overall NDVI increase of $8.83 \%$ from 1999 to 2013, but NDVI increased more apparently at lower elevations, whereas it remained relatively stable or even decreased at high elevations. In particular, $94.1 \%$ of the YZR basin experienced NDVI increases $(51.8 \%$ of these areas present a significant increase) (Figure $3 b, c)$. The overall pattern of the vegetation greening shows a positive correlation with increasing temperature $(r=0.587 ; p<0.05)$, but a negative relationship with decreasing precipitation $(r=-0.580 ; p<0.05)$. These results are consistent with other studies on the Tibetan Plateau [22,51] and the Himalayas [41]. Although the precipitation has been decreasing in the Southern Tibet in recent decades [26], enhanced warming can alter the heat and moisture transfer balance [22] and play a positive role in driving vegetation greening of the YZR basin since 1999. For instance, the annual NDVI decreased greatly in 2008 with low temperature and high precipitation, but increased in 2009 with high temperature and low precipitation (Figures 2 and 6). Our results are also consistent with previous findings that temperature is a dominant limiting factor for vegetation growth in Central Asia [8] and Arctic [3]. It is likely that rising temperature has driven the overall increase in vegetation across the YZR basin.

It is interesting that the greening rates are not fully associated with the rates of EDW (Figures $4 \mathrm{~b}$ and $5 b$ ). NDVI increases are more apparent at lower elevations (Figure $4 b$ ), in contrast to the pattern of EDW with higher warming rate at higher elevations. One potential reason for the inconsistency between the pattern of EDVG and EDW might result from the fact that the EDW in the YZR basin is not statistically significant. Although slightly higher warming rate occurs at higher elevations, the trend of the EDW rate from the 15 meteorological stations does not pass the significance level of $95 \%$ (Figure $5 b$ ). Lack of observational data above $4500 \mathrm{~m}$ limits our ability to interpret the general pattern of EDW in the YZR. Liu et al. (2009) used a large dataset of 116 meteorological stations in the eastern Tibetan Plateau, found that warming is more prominent at higher elevations than at lower elevations [45]. Based on Moderate Resolution Imaging Spectro-radiometer (MODIS) product, Qin et al. (2009) found that the warming rate becomes stable from $4800 \mathrm{~m}$ to $>6600 \mathrm{~m}$ with a slightly declining trend near the highest elevations, after an increase from $3000 \mathrm{~m}$ to $4800 \mathrm{~m}$ [10]. However, we found that most greening rates within the elevation bins of $>4500 \mathrm{~m}$ are minor $\left(<0.002 \mathrm{y}^{-1}\right)$ (Figure $4 \mathrm{~b}$ ). This indicates that the weak pattern of EDW in the YZR basin may blur the pattern of EDVG, but it is less likely to reverse the trend of vegetation greening at higher elevations. Therefore, other factors might contribute to the contrasting pattern between EDW and EDVG.

Precipitation is also crucial to vegetation growth [42], especially in the arid and semi-arid areas [52-54]. We found an overall decreasing trend in precipitation in the YZR basin during 1999-2013, which could have a negative impact to offset some of the NDVI increases driven by warming. However, the rate of precipitation change seems not to depend on elevation and cannot be used to explain EDVG. Note that the amount of precipitation decreases significantly with increasing elevation (Figure 8b), coincident with the decreasing greening rate with elevation in this basin (Figure $4 \mathrm{~b}$ ). Specifically, the spatially-averaged greening rate is $>0.0034 \mathrm{y}^{-1}$ in regions where TRMM-derived precipitation is $>800 \mathrm{~mm}$ and decreasing precipitation seems to have no negative effect on the NDVI increase in these regions. In contrast, the spatially-averaged greening rate is only $<0.0014 \mathrm{y}^{-1}$ in areas where TRMM-derived precipitation is $<500 \mathrm{~m}$ (corresponding elevation bins $>4000 \mathrm{~m}$ ) and many locations experienced NDVI decrease in these region, corresponding to decreasing precipitation (Figures $3 \mathrm{~b}$ and $8 \mathrm{~b}$ ). It seems that, in relatively humid areas (annual precipitation of $>800 \mathrm{~mm}$ ), vegetation growth is not sensitive to the variability of precipitation, and the temperature change is likely the dominant driver for the NDVI change. However, in relatively arid areas $(<500 \mathrm{~mm})$, precipitation becomes a major limiting factor for vegetation growth and the low precipitation may limit the NDVI increase at high elevations in the YZR basin. 
Some studies reported that environmental changes could alter vegetation phenology [51]. For example, the end date of vegetation growing season (EDS) on the Tibetan Plateau occurred earlier with increasing elevation during 1982-2011, the various vegetation types showed different phenological EDS timing [55]. In the YZR basin, the vegetation type of relatively high greening rates is mainly forest at lower elevations [56] with the multi-year average NDVI values of $>0.4$ (Figure 4a). However, we could not assess if the vegetation type alone would affect the greening rate in response to climate change, as the green-up date among different vegetation types is also determined primarily by the temperature and precipitation regimes associated with various elevation gradients [22,55]. These indicate that more studies are needed to clarify the biological processes of EDVG.

We also found that vegetation greening is partly affected by human activities in the YZR basin. For the past 20 years, a series of ecological protection projects, including afforestation, grassland protection, and vegetation recovery on sand dunes [57], have been implemented to prevent and restore degraded land. These ecological protection activities have resulted in rapid vegetation greening in some areas, such as wide valleys in the midstream, where the greening rates exceed $0.007 \mathrm{y}^{-1}$. However, some regions also suffer land degradation due to human activities. For example, NDVI decrease in some locations along highways and railways in the midstream is likely caused by road construction. NDVI decrease in regions around major cities, such as Lhasa and Zedang, is probably associated with urbanization.

\section{Conclusions}

The focus of this paper is to investigate the pattern of vegetation greening at different elevations in the YZR basin using SPOT NDVI data from 1999 to 2013, and examined its relationship with elevation-dependent changes in station-observed climatic factors (temperature and precipitation) and TRMM-derived precipitation. The annual NDVI has increased by $8.83 \%$ from 1999 to 2013 in the YZR basin with a NDVI increase rate of $0.0018 \mathrm{y}^{-1}$. About $94.1 \%$ of the YZR basin has experienced NDVI increase, $51.8 \%$ of which passed the $95 \%$ confidence level. The rate of vegetation greening varies with elevation, with a slight increase from elevation bins of $500 \mathrm{~m}$ to $2000 \mathrm{~m}$, a lesser increase from $2000 \mathrm{~m}$ to $4000 \mathrm{~m}$, and a relatively stable trend above $4000 \mathrm{~m}$. The most pronounced increase $\left(>0.007 \mathrm{y}^{-1}\right)$ occurred in some narrow belts along wide valleys in the midstream and in some patches in the low reaches, where elevations are generally $<3000 \mathrm{~m}$.

The temperature has been continuously increasing in the YZR basin since 1999, with a warming rate of $0.039{ }^{\circ} \mathrm{C} \cdot \mathrm{y}^{-1}$. The warming rate exhibits an increasing trend with increased elevation, but the trend is not statistical significant at the $95 \%$ level. The annual precipitation slightly decreases in 1999-2013, with a changing rate of $-9.33 \mathrm{~mm} \cdot \mathrm{y}^{-1}$. The precipitation decreases significantly as elevation increase, but its changing rate does not show a clear pattern along elevation gradients.

The vegetation greening is positively correlated with increasing temperature, but negatively related with decreasing precipitation. It seems that rising temperature has driven the basin-wide vegetation greening, but the greening rate is in contrast to the EDW pattern with more significant temperature increases at higher elevations. It appears that decreasing precipitation does not affect the overall increasing trend in NDVI, but relatively limited precipitation $(<500 \mathrm{~mm})$ may constrain the NDVI increases, causing apparently stable or even decreased NDVI at higher elevations $(>4000 \mathrm{~m})$. In addition, we also identified areas where NDVI changes may also be affected by human activities (both positively and negatively), such as afforestation and urbanization. These findings provide important insight into the climate change impact on alpine ecosystems and useful information to enhance the ecological protection and restoration on the Tibetan Plateau.

Acknowledgments: This work was funded by the National Natural Science Foundation of China (Grant No. 41301611; 41328001; and 31200534), the Natural Science Foundation of Jiangsu Province, China (Grant No. BK20130103), the State Scholarship Fund of China (Grant No. 201408320065), and the support from Department of Nature and Ecology Conservation, Ministry of Environmental Protection. The authors are indebted to the reviewers for their constructive comments and suggestions for improving the manuscript. 
We also would like to thank the Flemish Institute for Technological Research (VITO) and China Meteorological Data Sharing Service Network for kindly providing both the NDVI and climate data.

Author Contributions: H.L., Y.L., and J.J. conceived and designed the research; H.L., Y.L. and J.J. performed the analysis; W.S., Y.L., J.L., X.L., and X.X. contributed to the data analyisis and discussion; H.L., Y.L., and J.J. wrote the paper.

Conflicts of Interest: The authors declare no conflict of interest.

\section{References}

1. Beckage, B.; Osborne, B.; Gavin, D.G.; Pucko, C.; Siccama, T.; Perkin, T. A rapid upward shift of a forest ecotone during 40 years of warming in the Green Mountains of Vermont. Proc. Natl. Acad. Sci. USA 2008, 102, 4197-4202. [CrossRef] [PubMed]

2. Cong, N.; Piao, S.; Chen, A.; Wang, X.; Chen, S.; Han, S.; Zhou, G.; Zhang, X. Spring vegetation green-up date in China inferred from SPOT NDVI data: A multiple model analysis. Agric. For. Meteorol. 2012, 165, 104-113. [CrossRef]

3. Pearson, R.G.; Phillips, S.J.; Loranty, M.M.; Beck, P.S.A.; Damoulas, T.; Knight, S.J.; Goetz, S.J. Shifts in Arctic vegetation and associated feedbacks under climate change. Nat. Clim. Chang. 2013, 3, 673-677. [CrossRef]

4. Chen, H.; Zhu, Q.; Peng, C.; Wu, N.; Wang, Y.; Fang, X.; Gao, Y.; Zhu, D.; Yang, G.; Tian, J.; et al. The impacts of climate change and human activities on biogeochemical cycles on the Qinghai-Tibetan Plateau. Glob. Chang. Biol. 2013, 19, 2940-2955. [CrossRef] [PubMed]

5. Bhatt, U.S.; Walker, D.A.; Raynolds, M.K.; Bieniek, P.A.; Epstein, H.E.; Comiso, J.C.; Pinzon, J.E.; Tucker, C.J.; Polyakov, I.V. Recent declines in warming and vegetation greening trends over pan-Arctic tundra. Remote Sens. 2013, 9, 4229-4254. [CrossRef]

6. Hartmann, D.L.; Klein Tank, A.M.G.; Rusticucci, M.; Alexander, L.V.; Brönnimann, S.; Charabi, Y.; Dentener, F.J.; Dlugokencky, E.J.; Easterling, D.R.; Kaplan, A.; et al. Observations: Atmosphere and surface. In Climate Change 2013: The Physical Science Basis; Contribution of Working Group I to the Fifth Assessment Report of the Intergovernmental Panel on Climate Change; Cambridge University Press: Cambridge, UK; New York, NY, USA, 2013; pp. 195-254.

7. Raynolds, M.K.; Walker, D.A.; Maier, H.A. NDVI patterns and phytomass distribution in the circumpolar Arctic. Remote Sens. Environ. 2006, 102, 271-281. [CrossRef]

8. Mohammat, A.; Wang, X.; Xu, X.; Peng, L.; Yang, Y.; Zhang, X.; Myneni, R.B.; Piao, S. Drought and spring cooling induced recent decrease in vegetation growth in Inner Asia. Agric. For. Meteorol. 2013, 178-179, 21-30. [CrossRef]

9. Xing, P.; Zhang, Q.; Lv, L. Absence of late-summer warming trend over the past two and half centuries on the eastern Tibetan Plateau. Glob. Planet. Chang. 2014, 123, 27-35. [CrossRef]

10. Qin, J.; Yang, K.; Liang, S.; Guo, X. The altitudinal dependence of recent rapid warming. Clim. Chang. 2009, 97, 321-327. [CrossRef]

11. Rangwala, I.; Miller, J.R. Climate change in mountains: A review of elevation-dependent warming and its possible causes. Clim. Chang. 2012, 114, 527-547. [CrossRef]

12. Trujillo, E.; Molotch, N.P.; Goulden, M.L.; Kelly, A.E.; Bales, R.C. Elevation-dependent influence of snow accumulation on forest greening. Nat. Geosci. 2012, 5, 705-709. [CrossRef]

13. Pepin, N.; Bradeley, B.S.; Diaz, H.F.; Baraer, M.; Caceres, E.B.; Forsythe, N.; Fowler, H.; Greenwood, G.; Hashmi, M.Z.; Liu, X.D.; et al. Elevation-dependent warming in mountain regions of the world. Nat. Clim. Chang. 2015, 5, 424-430. [CrossRef]

14. Cao, M.K.; Woodward, F.I. Dynamic responses of terrestrial ecosystem carbon cycling to global climate change. Nature 1998, 393, 249-252. [CrossRef]

15. De Jong, R.; de Bruin, S.; de Wit, A.; Schaepman, M.E.; Dent, D.L. Analysis of monotonic greening and browning trends from global NDVI time-series. Remote Sens. Environ. 2011, 115, 692-702. [CrossRef]

16. Myneni, R.; Keeling, C.; Tucker, C.J.; Asrar, G.; Nemani, R. Increased plant growth in the northern high latitudes from 1981 to 1991. Nature 1997, 386, 698-702. [CrossRef]

17. You, Q.; Kang, S.; Pepin, N.; Flügel, W.A.; Yan, Y.; Behrawan, H.S.; Huang, J. Relationship between temperature trend magnitude, elevation and average temperature in the Tibetan Plateau from homogenized surface stations and reanalysis data. Glob. Planet. Chang. 2010, 71, 124-133. [CrossRef] 
18. Zhang, L.; Ma, Y.; Salama, M.S.; Su, Z. Assessment of vegetation dynamics and their response to variations in precipitation and temperature in the Tibetan Plateau. Clim. Chang. 2010, 103, 519-535.

19. Piao, S.; Wang, X.; Ciais, P.; Zhu, B.; Wang, T.; Liu, J. Changes in satellite-derived vegetation growth trend in temperate and boreal Eurasia from 1982 to 2006. Glob. Chang. Biol. 2011, 17, 3228-3239. [CrossRef]

20. Wang, X.; Piao, S.; Ciais, P.; Li, J.; Friedlingstein, P.; Koven, C.; Chen, A. Spring temperature change and its implication in the change of vegetation growth in North America from 1982 to 2006. Proc. Natl. Acad. Sci. USA 2011, 108, 1240-1245. [CrossRef] [PubMed]

21. Beniston, M.; Diaz, H.F.; Bradley, R.S. Climatic change at high elevation sites: An overview. Clim. Chang. 1997, 36, 233-251. [CrossRef]

22. Shen, M.; Zhang, G.; Cong, N.; Wang, S.; Kong, W.; Piao, S. Increasing altitudinal gradient of spring vegetation phenology during the last decade on the Qinghai-Tibetan Plateau. Agric. For. Meteorol. 2014, 189-190, 71-80. [CrossRef]

23. Nemani, R.R.; Keeling, C.D.; Hashimoto, H.; Jolly, W.M.; Piper, S.C.; Tucker, C.J.; Myneni, R.B.; Running, S.W. Climate-driven increases in global terrestrial net primary production from 1982 to 1999. Science 2003, 300, 1560-1563. [CrossRef] [PubMed]

24. Wu, D.; Zhao, X.; Liang, S.; Zhou, T. Time-lag effects of global vegetation responses to climate change. Glob. Chang. Biol. 2015. [CrossRef] [PubMed]

25. Piao, S.; Tan, T.; Nan, H.; Ciais, P.; Fang, J.; Wang, T.; Vuichard, N.; Zhu, B. Impacts of climate and $\mathrm{CO}_{2}$ changes on the vegetation growth and carbon balance of Qinghai-Tibetan grasslands over the past five decades. Glob. Planet. Chang. 2012, 98-99, 73-80. [CrossRef]

26. Li, Y.; Liao, J.; Guo, H.; Liu, Z.; Shen, G. Patterns and potential drivers of dramatic changes in Tibetan Lakes, 1972-2010. PLoS ONE 2014, 9, 1-12. [CrossRef] [PubMed]

27. Liu, X.; Chen, B. Climatic warming in the Tibetan Plateau during recent decades. Int. J. Climatol. 2000, 20, 1729-1742. [CrossRef]

28. Tao, J.; Zhang, Y.; Dong, J.; Fu, Y.; Zhu, J.; Zhang, G.; Jiang, Y.; Tian, L.; Zhang, X.; Zhang, T.; et al. Elevation-dependent relationships between climate change and grassland vegetation variation across the Qinghai-Xizang Plateau. Int. J. Climatol. 2015, 35, 1638-1647. [CrossRef]

29. Qiu, J. Double threat for Tibet. Nature 2014, 512, 240-241. [CrossRef] [PubMed]

30. Li, H.; Shen, W.; Zou, C.; Jiang, J.; Fu, L.; She, G. Spatio-temporal variability of soil moisture and its effect on vegetation in a desertified aeolian riparian ecotone on the Tibetan Plateau, China. J. Hydrol. 2013, 479, 215-225. [CrossRef]

31. Qiu, J. Droughts threaten high-altitude Himalayan forests. Nature 2015. [CrossRef]

32. Liu, Z.; Yao, Z.; Huang, H.; Wu, S.; Liu, G. Land use and climate changes and their impacts on runoff in the Yarlung Zangbo River basin, China. Land Degrad. Dev. 2014, 25, 203-215. [CrossRef]

33. Verbyla, D. The greening and browning of Alaska based on 1982-2003 satellite data. Glob. Ecol. Biogeogr. 2008, 17, 547-555. [CrossRef]

34. Jia, G.J.; Epstein, H.E.; Walker, D.A. Vegetation greening in the Canadian Arctic related to decadal warming. J. Environ. Monitor. 2009, 11, 2231-2238. [CrossRef] [PubMed]

35. Nash, M.S.; Bradford, D.F.; Wickham, J.D.; Wade, T.G. Detecting change in landscape greenness over large areas: An example for New Mexico, USA. Remote Sens. Environ. 2014, 150, 152-162. [CrossRef]

36. Chen, H. Assessment of hydrological alterations from 1961 to 2000 in the Yarlung Zangbo River, Tibet. Ecohydrol. Hydrobiol. 2012, 12, 93-103. [CrossRef]

37. Shen, W.; Li, H.; Sun, M.; Jiang, J. Dynamics of aeolian sandy land in the Yarlung Zangbo River basin of Tibet, China from 1975 to 2008. Glob. Planet. Chang. 2012, 86-87,37-44. [CrossRef]

38. Chen, B.; Li, H.; Cao, X.; Shen, W.; Jin, H. Vegetation pattern and spatial distribution of NDVI in the Yarlung Zangbo River basin of China. J. Desert Res. 2015, 35, 120-128. (In Chinese)

39. Li, H. Remote Sensing Monitoring and Vegetation Restoration Experiments on Aeolian Sandy Land in the Yarlung Zangbo River Basin on the Tibetan Plateau. Doctor's Thesis, Nanjing Forestry University, Nanjing, China, 2012. (In Chinese)

40. Yang, Y.; Piao, S. Variations in grassland vegetation cover in relation to climatic factors on the Tibetan Plateau. J. Plant Ecol. 2006, 30, 1-8. 
41. Zhang, Y.; Gao, J.; Liu, L.; Wang, Z.; Ding, M.; Yang, X. NDVI-based vegetation changes and their responses to climate change from 1982 to 2011: A case study in the Koshi River Basin in the middle Himalayas. Glob. Planet. Chang. 2013, 108, 139-148. [CrossRef]

42. Barbosa, H.A.; Lakshmi Kumar, T.V.; Silva, L.R.M. Recent trends in vegetation dynamics in the South America and their relationship to rainfall. Nat. Hazards 2015, 77, 883-899. [CrossRef]

43. Maisongrande, P.; Duchemin, B.; Dedieu, G. VEGETATOPM/SPOT_An operational mission for the earth monitoring: Presentation of new standard products. Int. J. Remote Sens. 2004, 25, 9-14. [CrossRef]

44. Huffman, G.J.; Adler, R.F.; Bolvin, D.T.; Gu, G.; Nelkin, E.J.; Bowman, K.P.; Hong, Y.; Stocker, E.F.; Wolff, D.B. The TRMM Multisatellite Precipitation Analysis (TPMA): Quasi-global, multiyear, combined-sensor precipitation estimates at fine scales. J. Hydrometeorol. 2007, 8, 38-55. [CrossRef]

45. Liu, X.; Cheng, Z.; Yan, L.; Yin, Z. Elevation dependency of recent and future minimum surface air temperature trends in the Tibetan Plateau and its surroundings. Glob. Planet. Chang. 2009, 68, 164-174. [CrossRef]

46. Guo, W.; Liu, S.; Yao, X.; Xu, J.; Shangguan, D.; Wu, L.; Zhao, J.; Liu, Q.; Jiang, Z.; Wei, J.; et al. The Second Glacier Inventory Dataset of China (Version 1.0); Cold and Arid Regions Science Data Center at Lanzhou: Lanzhou, China, 2014. [CrossRef]

47. Mann, H.B. Non-parametric tests against trend. Econometrica 1945, 13, 163-171. [CrossRef]

48. Zhou, L.; Tucker, C.J.; Kaufmann, R.K.; Slayback, D.; Shabanov, N.V.; Myneni, R.B. Variations in northern vegetation activity inferred from satellite data of vegetation index during 1981 to 1999. J. Geophys. Res. 2001, 106, 20069-20083. [CrossRef]

49. Angert, A.; Biraud, S.; Bonfils, C.; Henning, C.C.; Buermann, W.; Pinzon, J.; Fung, I. Drier summers cancel out the $\mathrm{CO}_{2}$ uptake enhancement induced by warmer springs. Proc. Natl. Acad. Sci. USA 2005, 102, 10823-10827. [CrossRef] [PubMed]

50. Zhang, G.; Zhang, Y.; Dong, J.; Xiao, X. Green-up dates in the Tibetan Plateau have continuously from 1982 to 2011. Proc. Natl. Acad. Sci. USA 2013, 110, 4309-4314. [CrossRef] [PubMed]

51. Piao, S.; Cui, M.; Chen, A.; Wang, X.; Ciais, P.; Liu, J.; Tang, Y. Altitude and temperature dependence of change in the spring vegetation green-up date from 1982 to 2006 in the Qinghai-Xizang Plateau. Agric. For. Meteorol. 2011, 151, 1599-1608. [CrossRef]

52. Lotsch, A.; Friedl, M.A.; Anderson, B.T.; Tucker, C.J. Coupled vegetation-precipitation variability observed from satellite and climate records. Geophys. Res. Lett. 2003, 30, 81-84.

53. Rowe, A.K.; Rutledge, S.A.; Lang, T.J.; Ciesielski, P.E.; Saleeby, Y.S. Elevation-dependent trends in precipitation observed during NAME. Mon. Weather Rev. 2008, 136, 4962-4978. [CrossRef]

54. Shen, M.; Piao, S.; Cong, N.; Zhang, G.; Jassens, I.A. Precipitation impacts on vegetation spring phenology on the Tibetan Plateau. Glob. Chang. Biol. 2015. [CrossRef] [PubMed]

55. Che, M.; Chen, B.; Innes, J.L.; Wang, G.; Dou, X.; Zhou, T.; Zhang, H.; Yan, J.; Xu, G.; Zhao, H. Spatial and temporal variations in the end date of the vegetation growing season throughout the Qinghai-Tibetan Plateau from 1982 to 2011. Agric. For. Meteorol. 2014, 189, 81-90. [CrossRef]

56. Chen, X.; An, S.; Inouye, D.W.; Schwartz, M.D. Temperature and snowfall trigger alpine vegetation green-up on the world's roof. Glob. Chang. Biol. 2015, 21, 3635-3646. [CrossRef] [PubMed]

57. Li, H.; Qin, W.; Zhang, T.; Shen, W. Comprehensive evaluation model for revegetation potentiality on moving sandy land in alpine valley of Tibet, China. Trans. CSAE 2015, 31, 220-228.

(C) 2015 by the authors; licensee MDPI, Basel, Switzerland. This article is an open access article distributed under the terms and conditions of the Creative Commons by Attribution (CC-BY) license (http:/ / creativecommons.org/licenses/by/4.0/). 